\title{
Влияние температуры электролита на процесс катодного осаждения нитевидных наноструктур Ge из водных растворов на частицах In и Sn
}

\author{
(С) И.М. Гаврилин ${ }^{1}$, Д.Г. Громов ${ }^{1}$, А.А. Дронов ${ }^{1}$, С.В. Дубков ${ }^{1}$, Р.Л. Волков ${ }^{1}$, А.Ю. Трифонов ${ }^{1,2}$, \\ Н.И. Боргардт ${ }^{1}$, С.А. Гаврилов ${ }^{1}$ \\ ${ }^{1}$ Национальный исследовательский университет „Московский институт электронной техники“, \\ 124498 Москва, Зеленоград, Россия \\ ${ }^{2}$ Научно-исследовательский институт физических проблем им. Ф.В. Лукина, \\ 124460 Москва, Зеленоград, Россия \\ E-mail: gavrilin.ilya@gmail.com
}

(Получена 12 декабря 2016 г. Принята к печати 1 февраля 2017 г.)

Представлены результаты исследования роста нитевидных структур Ge из водных растворов электролитов при различных температурах с использованием массивов наночастиц In и $\mathrm{Sn}$ в качестве центров кристаллизации. Температура процесса катодного осаждения Ge из водных растворов оказывает существенное влияние на строение слоя, осаждаемого на поверхность. При наличии частиц металлов в расплавленном состоянии происходит рост нитевидных структур $\mathrm{Ge}$ за счет катодного восстановления ионов, содержащих $\mathrm{Ge}$, на поверхности электрода с последующим растворением и кристаллизацией в расплаве на границе с подложкой. Полученные результаты показывают решающую роль наличия жидких частиц металла в процессе электрохимического формирования нитевидных нанокристаллов германия.

DOI: $10.21883 /$ FTP.2017.08.44799.8482

\section{1. Введение}

Нитевидные наноструктуры Ge благодаря своим электрофизическим и оптическим свойствам имеют широкий спектр применения: в литий-ионных аккумуляторах [1], фотовольтаике [2], устройствах памяти [3], оптике [4], наноэлектромеханических системах [5]. Для формирования полупроводниковых нанонитей $\mathrm{Ge}$ в основном используется газофазное осаждение [6]. Однако процессы газофазного осаждения зачастую требуют использования сложного технологического оборудования и осуществляются при достаточно высоких температурах, что не всегда приемлемо как с технологической, так и с экономической точки зрения.

Также известны электрохимические методы получения наноструктур германия. Катодная поляризация твердотельных электродов в водных растворах, содержащих ионы германия, обеспечивает образование пленок толщиной всего в несколько монослоев [7], поскольку высокая химическая активность Ge по отношению к молекулам $\mathrm{H}_{2} \mathrm{O}$ препятствует осаждению пленок значительной толщины, а также нитевидных кристаллов. Избежать взаимодействия кристаллизующегося $\mathrm{Ge}$ с $\mathrm{H}_{2} \mathrm{O}$ можно за счет использования ионных жидкостей [8] или расплавов солей германия [9]. Однако для формирования массивов наноструктур $\mathrm{Ge}$ из неводных электролитов необходимо использование поликарбонатных мембран [10], либо самоупорядоченных пористых матриц, например, оксида алюминия [11]. Более того, сформированные наноструктуры Ge из неводных электролитов имеют аморфную структуру, поэтому после их формирования необходима термическая обработка, что также усложняет технологический процесс и ограничивает условия их применения.
В работах $[12,13]$ была продемонстрирована возможность электрохимического осаждения нитевидных наноструктур $\mathrm{Ge}$ из водных растворов без использования темплатов. Особенностью этого метода является использование расплавленных частиц металлов, таких как $\mathrm{Hg}$ и $\mathrm{Ga}$, в качестве центров кристаллизации. Авторы работ $[12,13]$ считают, что жидкий металл служит электродом для восстановления ионов, содержащих $\mathrm{Ge}$, до германия в атомарном состоянии, с их последующим растворением и образованием расплава эвтектического состава. Непрерывная реакция катодного восстановления обеспечивает концентрационное перенасыщение расплава германием, в результате чего происходит кристаллизация $\mathrm{Ge}$ в расплаве на границе с подложкой. При этом расплав предотвращает взаимодействие $\mathrm{Ge}$ с молекулами $\mathrm{H}_{2} \mathrm{O}$ и образование оксидных и гидроксидных соединений. Таким образом, на границе жидкий металл-подложка происходит рост германия по аналогии с ростом вискеров из газовой фазы по известному механизму пар-жидкость-кристалл [6].

Однако при использовании $\mathrm{Hg}$ и $\mathrm{Ga}$ наряду с существующими технологическими проблемами часто наблюдается коалесценция и растекание жидких частиц на подложке [14], что затрудняет контроль их размеров и, как следствие, размеров нитей Ge. C этой точки зрения, альтернативой является применение легкоплавких металлов, которые могут образовывать с Ge сплавы эвтектического состава и обладают более высокой температурой плавления, чем $\mathrm{Hg}$ и $\mathrm{Ga}$. Также следует учитывать, что максимально достижимая температура процесса осаждения ограничена температурой кипения электролита. Для водных растворов эта температура составляет $\sim 100^{\circ} \mathrm{C}$. Так, в работе [15] была показана 

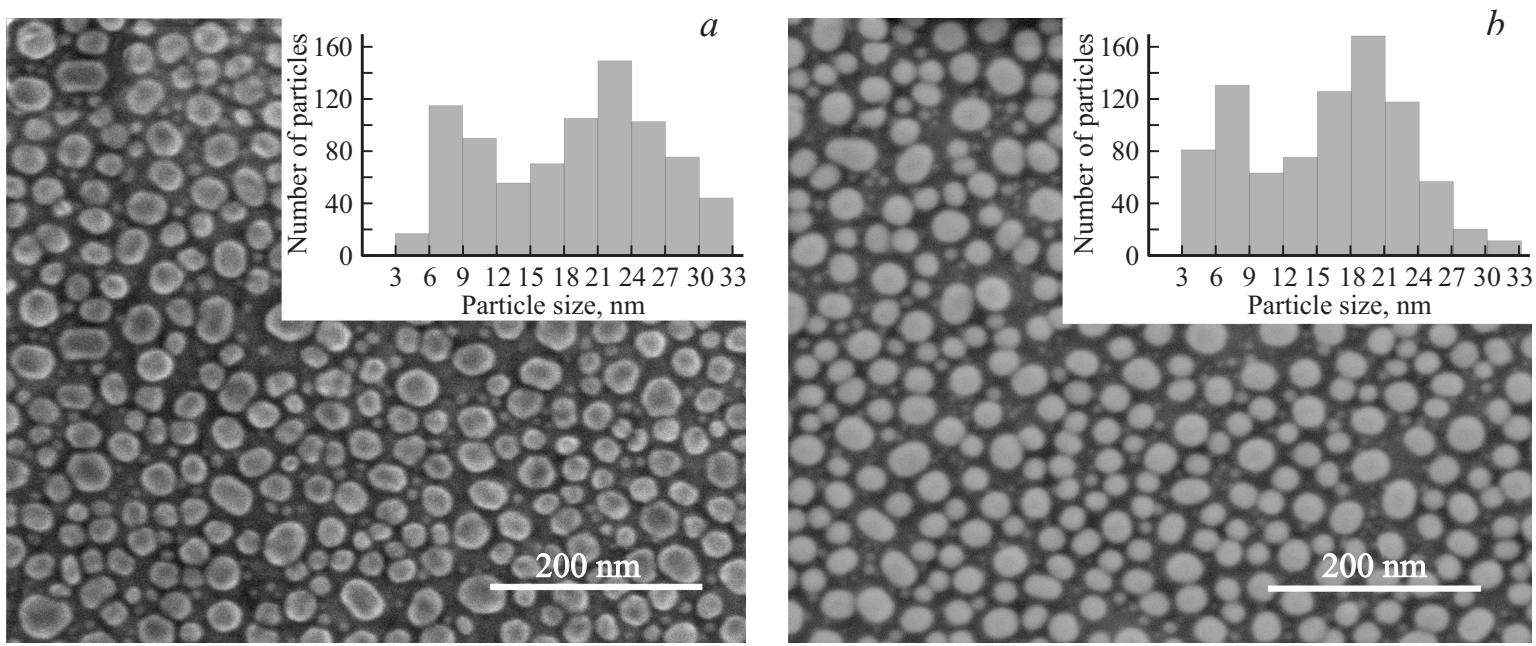

Рис. 1. РЭМ-изображения массивов наночастиц металлов на поверхности $\mathrm{Si}$ с нанесенной пленкой W: $a-\mathrm{In}$ и $b-\mathrm{Sn}$. На вставках представлены гистограммы распределения частиц по размерам для соответствующих металлов.

возможность роста нитевидных структур германия из водных растворов с использованием частиц In с размерами, не превышающими 100 нм (температура плавления объемного In составляет $\left.\sim 156.6^{\circ} \mathrm{C}\right)$. Известно, что температура плавления снижается с уменьшением размеров металлических частиц [16]. Однако в работе [15] сделано только лишь предположение о возможном расплавлении частиц металла в ходе процесса роста.

В настоящей работе на основе сравнения результатов теоретического расчета температур плавления наночастиц In и Sn различного диаметра и данных электронной микроскопии о морфологии наноструктур $\mathrm{Ge}$, полученных катодным осаждением на массиве частиц металлов из водного раствора при температурах $20-90^{\circ} \mathrm{C}$, показана определяющая роль наличия расплава наночастиц металла для обеспечения электрохимического формирования нитевидных нанокристаллов Ge.

\section{2. Методика проведения эксперимента}

В качестве подложек для электрохимического осаждения использовали полированные пластины монокристаллического $\mathrm{Si} p$-типа с удельным сопротивлением 10 Ом · см. Размер экспериментальных образцов составлял $1 \times 2$ см. На поверхность подложек последовательно наносили пленку $\mathrm{W}$ толщиной 100 нм и массивы наночастиц In или Sn. Пленку W получали методом магнетронного распыления. Выбор W обусловлен низкой шероховатостью поверхности его слоев и малым сопротивлением, необходимым для обеспечения равномерного токоподвода по площади поверхности осаждения. Для формирования массива сферических наночастиц металлов заданного среднего размера использовали методику [17]. In и Sn наносили вакуум-термическим испарением навесок вещества массой 3 мг с молибденового испарителя при остаточном давлении $1 \cdot 10^{-5}$ торр и расстоянии от испарителя до подложки $20 \mathrm{~cm}$. После нанесения металлов образцы отжигали в вакууме при $150^{\circ} \mathrm{C}$ в течение 10 мин.

Электрохимическое осаждение проводили в трехэлектродной ячейке, в качестве противоэлектрода использовали платиновую пластину размером $1.4 \times 1.5 \mathrm{~cm}$, в качестве электрода сравнения - стандартный каломельный электрод $\left(\mathrm{Pt}|\mathrm{Hg}| \mathrm{Hg}_{2} \mathrm{Cl}_{2} \mid \mathrm{KCl}^{-}\right)$. Осаждение проводили в растворе электролита, аналогичном предложенному в работе [18]. Раствор содержал $0.05 \mathrm{M}$ оксида германия (IV) $\mathrm{GeO}_{2}, 0.5 \mathrm{M}$ сульфата калия $\mathrm{K}_{2} \mathrm{SO}_{4}$ в качестве индифферентного электролита и $0.5 \mathrm{M}$ янтарной кислоты в качестве буферирующей добавки. Величину $\mathrm{pH}$ раствора доводили до 6.5 путем добавления $\mathrm{NH}_{4} \mathrm{OH}$. Температуру раствора контролировали с помощью термостата LAUDA Alpha. Осаждение проводили при потенциале -1.3 В относительно стандартного каломельного электрода сравнения в течение 10 мин при различных температурах раствора. Потенциал задавали с помощью потенциостата-гальваностата „Элинс Р-45X“. Полученные образцы промывали в деионизованной воде и сушили в потоке аргона.

Полученные структуры исследовали методами растровой электронной микроскопии (РЭМ) в электронноионном микроскопе FEI Helios NanoLab 650 и просвечивающей электронной микроскопии (ПЭМ) в микроскопе FEI Tecnai $\mathrm{G}^{2} 20$ S-Twin.

Для анализа ПЭМ нитевидные структуры Ge удаляли с поверхности подложки механическим способом и переносили на стандартную медную сетку для ПЭМ.

\section{3. Экспериментальные результаты}

На рис. 1 представлены РЭМ-изображения массива частиц In и $\mathrm{Sn}$ на поверхности экспериментальных образцов, а также гистограммы их распределения по размерам. 

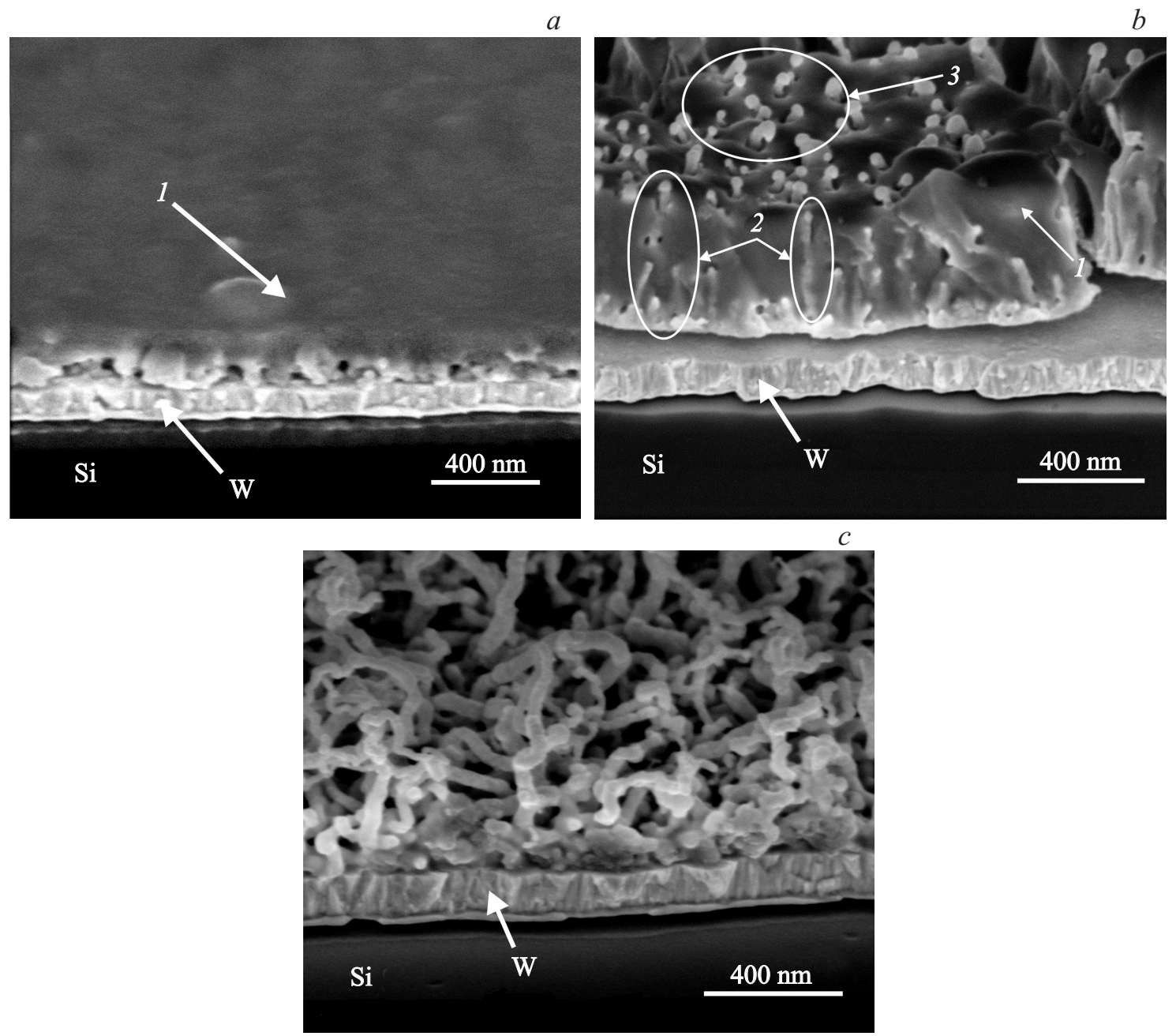

Рис. 2. РЭМ-изображения поперечного скола структур, сформированных катодным осаждением на частицах In при различных температурах раствора: $a-20^{\circ} \mathrm{C}, b-40^{\circ} \mathrm{C} ; c-60^{\circ} \mathrm{C}$. $1-$ сплошной слой, $2-$ нитевидные включения, $3-$ частицы сферической формы.

Как следует из представленных на рис. 1 гистограмм, массивы наночастиц характеризуются наличием двух преобладающих размеров: 6-9 и 21-24 нм для In и 6-9 и $18-21$ нм для $\mathrm{Sn}$.

На рис. 2 представлены РЭМ-изображения поперечного скола структур, сформированных катодным осаждением из водного раствора при различных температурах.

Как можно видеть, температура процесса оказывает существенное влияние на строение слоя, осаждаемого на поверхность образцов, покрытых частицами In. Так, при $20^{\circ} \mathrm{C}$ формируется сплошной слой, не содержащий нитевидных включений $(1$ на рис. $2, a)$. При температуре раствора $40^{\circ} \mathrm{C}$ в сплошном слое появляются нитевидные включения (2 на рис. $2, b)$, а на вершинах некоторых нитей наблюдаются частицы сферической формы с диаметрами близкими диаметрам исходных частиц металла (3 на рис. $2, b)$. При более высокой температуре раствора электролита $\left(60^{\circ} \mathrm{C}\right)$ образуется массив нитевидных структур без какого-либо сплошного слоя (рис. 2, c). При

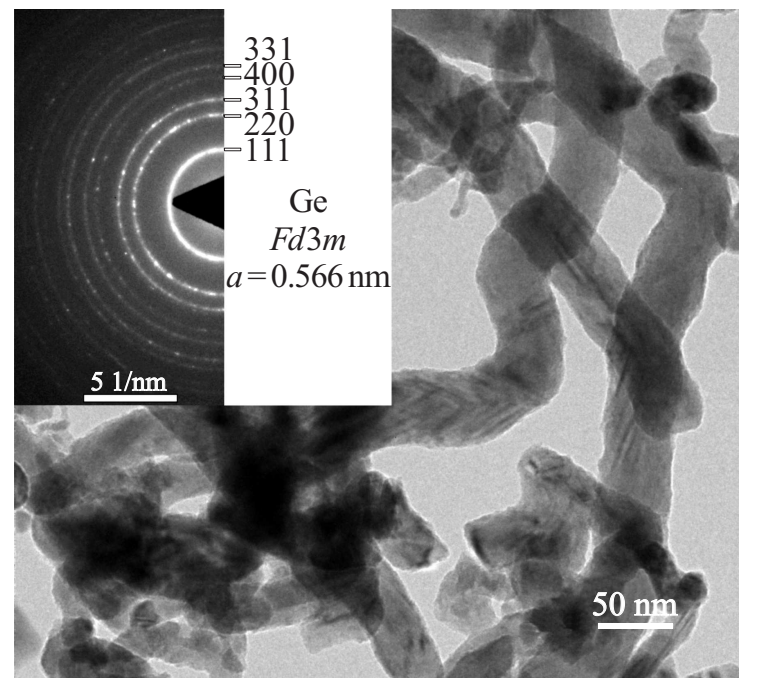

Рис. 3. ПЭМ-изображение нитей $\mathrm{Ge}$, сформированных на частицах In при температуре раствора $60^{\circ} \mathrm{C}$. На вставке представлена дифракционная картина, полученная от области диаметром 1 мкм. 
осаждении на поверхность, покрытую частицами $\mathrm{Sn}$, при всех температурах, включая $90^{\circ} \mathrm{C}$, формировался только сплошной слой.

На рис. 3 представлены результаты исследования методами ПЭМ нитей Ge, сформированных при температуре раствора $60^{\circ} \mathrm{C}$. Дифракционная картина, полученная от области диаметром 1 мкм, соответствует поликристаллу германия, имеющему решетку типа алмаз (с постоянной решетки $a=0.566$ нм).

\section{4. Обсуждение}

Анализ зависимости результатов электронной микроскопии осаждаемых слоев от температуры раствора и типа наночастиц металла, на которых протекает процесс, позволяет предположить ключевую роль плавления наночастиц металла в обеспечении катодного осаждения нитевидных нанокристаллов Ge из водных растворов.

Исследованные в данной работе In и $\mathrm{Sn}$ имеют температуры плавления объемных кристаллов, значительно превышающие температуру кипения водного электролита. Однако если металлы присутствуют в системе в виде наночастиц, то температура их плавления может существенно снижаться с уменьшением размеров частиц в связи с заметным вкладом поверхностной энергии в суммарную энергию системы $[16,19]$.

Для анализа вероятности нахождения изученных частиц в жидком состоянии при заданной температуре раствора, в котором проводили катодное осаждение, можно применить подход, разработанный нами в работе [16]. В ней обоснована зависимость температуры плавления сферической частицы от ее радиуса:

$$
T=T_{\infty}\left(\frac{\Delta H(T)}{\Delta H\left(T_{\infty}\right)}+\frac{3 \Delta \delta}{r \Delta H\left(T_{\infty}\right)}\right),
$$

где $T_{\infty}-$ справочная температура плавления объемного металла, $\Delta \delta=\delta_{L}-\delta_{S}-$ изменение поверхностной энергии системы при переходе из твердого в жидкое состояние, $\Delta H_{m}\left(T_{\infty}\right)$ - теплота плавления при температуре плавления объемного материала, $\Delta H_{m}(T)-$ теплота плавления при температуре плавления частицы $T$. Температурная зависимость теплоты плавления (уравнение Кирхгоффа) имеет вид:

$$
\Delta H_{m}(T)=\Delta H_{\infty}+\int_{T_{\infty}}^{T} \Delta C_{p} d T,
$$

где $\Delta C_{p}=C_{p}^{L}-C_{p}^{S}-$ изменение теплоемкости при переходе из твердого в жидкое состояние.

На основании уравнений (1) и (2) в соответствии с данной методикой были получены теоретические зависимости температуры плавления частицы от еe диаметра для In и Sn. Для расчетов температуры плавления использовали справочные величины поверхностного натяжения [20] для In:

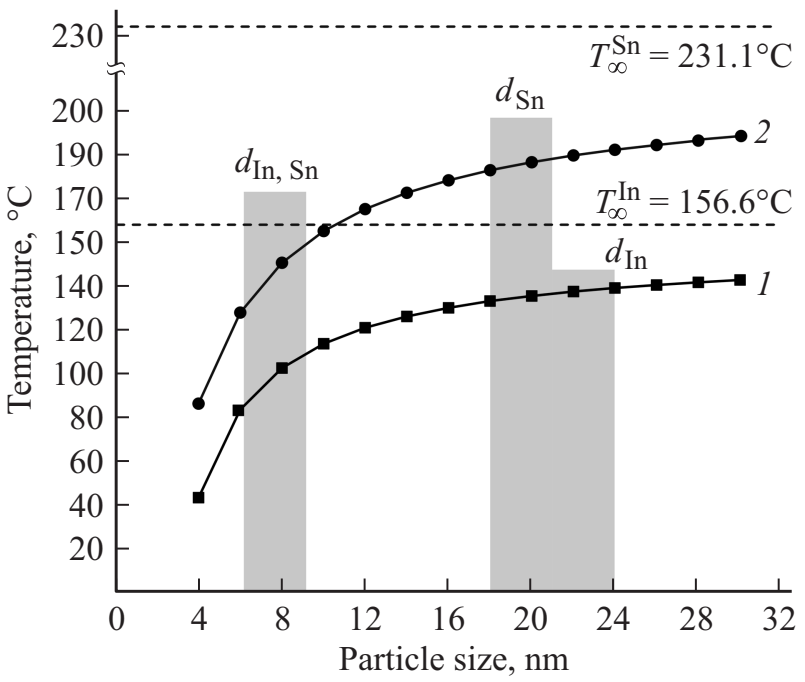

Рис. 4. Теоретические зависимости температуры плавления частиц металла. Кривые: 1 - In, 2 - Sn. Заштрихованные области показывают, при каких температурах, согласно расчету, полученные нами экспериментальные частицы Sn и In должны переходить в жидкое состояние.

$\delta_{L}=556 \mathrm{MH} / \mathrm{M}\left(\right.$ при $\left.T=200^{\circ} \mathrm{C}\right)$ и $\delta_{S}=633 \mathrm{мДж} / \mathrm{M}^{2}$ (при $T=142^{\circ} \mathrm{C}$ ); для $\mathrm{Sn}: \delta_{L}=530 \mathrm{MH} / \mathrm{M}\left(\right.$ при $T=300^{\circ} \mathrm{C}$ ) и $\delta_{S}=673 \mathrm{мДж} / \mathrm{M}^{2}$ (при $T=215^{\circ} \mathrm{C}$ ). При расчете теплоты плавления использовали температурные зависимости теплоемкости для объемного материала [21,22]: для $\operatorname{In} C_{p}^{S}=18.297+24.172 \cdot 10^{-3} T+1.241 \cdot 10^{5} T^{-2}$ в твердом состоянии и $C_{p}^{L}=27.156-1.092 \cdot 10^{-3} T$ $+4.234 \cdot 10^{5} T^{-2}+0.502 \cdot 10^{-6} T^{2}$ в жидком состоянии; для $\mathrm{Sn} C_{p}^{S}=34.297-29.957 \cdot 10^{-3} T-2.461 \cdot 10^{5} T^{-2}$ $+50.794 \cdot 10^{-6} T^{2}$ в твердом состоянии и $C_{p}^{L}=25.184$ $+2.105 \cdot 10^{-3} T+8.188 \cdot 10^{5} T^{-2}-0.163 \cdot 10^{-6} T^{2}$ в жидком. Результаты расчета представлены на рис. 4.

Из результатов расчета следует, что температура плавления индия и олова с учетом размерного эффекта в диапазоне размеров частиц до 50 нм заметно ниже справочных значений для объемных материалов, и особенно резко она начинает снижаться при размерах меньше 10 нм. Причем для $\mathrm{Sn}$ в целом имеет место более ощутимое снижение. В частности, для частиц диаметром 10 нм понижение температуры плавления для In может составлять $\sim 50^{\circ} \mathrm{C}$, а для $\mathrm{Sn} \sim 80^{\circ} \mathrm{C}$.

Расчеты показывают, что частицы $\mathrm{Sn}$ размером $18-22$ нм, и даже 6-9 нм будут плавиться при температурах заметно выше $100^{\circ} \mathrm{C}$ (рис. 4, кривая 2). Действительно, рост нитевидных кристаллов Ge при осаждении в водных растворах в изученном диапазоне температур, включая $90^{\circ} \mathrm{C}$, не наблюдается.

Согласно расчетам, частицы In размером 6-9 нм с большой вероятностью находятся в расплавленном состоянии при температуре $\sim 90^{\circ} \mathrm{C}$, а частицы размером 21-24 нм должны расплавиться при температуре выше $100^{\circ} \mathrm{C}$ (рис. 4, кривая 1). Тем не менее наши 
экспериментальные результаты показали, что уже при температуре раствора $40^{\circ} \mathrm{C}$ на катоде частично формируются нитевидные структуры Ge (рис. 2, $b$ ).

Диаграммы фазовых равновесий систем $\mathrm{Ge}-\mathrm{In}$ и $\mathrm{Ge}-\mathrm{Sn}[23]$ имеют схожий эвтектический тип и, в основном, различаются температурами. Таким образом, отсутствие роста на Sn и его наличие на In, а также сопоставление полученных нами экспериментальных результатов с результатами работ $[12,13,15]$ указывают на то, что основополагающую роль для синтеза нитевидных нанокристаллов $\mathrm{Ge}$ из водного раствора является наличие частиц металла в жидком состоянии.

Наблюдаемое различие между расчетной температурой плавления частиц индия и экспериментальной температурой, при которой мы наблюдаем синтез нанокристаллического $\mathrm{Ge}$, можно объяснить несколькими причинами. Во-первых, в расчетах не учтена температурная зависимость поверхностной энергии, а использовано постоянное справочное значение, полученное при фиксированной температуре. Во-вторых, не было учтено поверхностное натяжение границы раздела электролит-расплав. В-третьих, температурные зависимости теплоемкостей жидкой и твердой фаз для частиц могут отличаться от соответствующих справочных зависимостей, полученных для объемных фаз. Это также может привести к более существенному снижению температуры плавления частицы по сравнению с объемным материалом. Более того, в работе [24] показано, что с уменьшением размеров имеют место смещение в область более низких температур и трансформация всей фазовой диаграммы системы. В частности, температура эвтектики может снижаться на 20\% [25].

\section{5. Заключение}

Таким образом, проведенные теоретические расчеты температуры плавления наночастиц In и Sn и экспериментальные результаты показывают решающую роль наличия жидких частиц металла в процессе электрохимического формирования нитевидных нанокристаллов германия.

Проведенные расчеты температур плавления In и $\mathrm{Sn}$ показывают возможность перехода частиц в жидкое состояние при температурах существенно ниже справочной температуры плавления.

Температура процесса катодного осаждения Ge из водных растворов оказывает существенное влияние на строение слоя осаждаемого на поверхность.

При наличии частиц металлов в расплавленном состоянии происходит рост нитевидных структур $\mathrm{Ge}$ за счет катодного восстановления Ge-содержащих ионов на поверхности электрода с последующим растворением и кристаллизацией в расплаве на границе с подложкой.

Сопоставление проведенных теоретических расчетов с результатами экспериментальных исследований позволило предположить возможные дополнительные факто- ры, обеспечивающие значительное понижение температуры плавления.

Предложенный в данной работе подход можно использовать для расширения спектра используемых частиц металлов и управления составом и морфологией формируемых нанонитей.

Работа выполнена в рамках проведения работ по государственному заданию №16.2653.2017/ПЧ.

\section{Список литературы}

[1] S. Wu, C. Han, J. Iocozzia, M. Lu, R. Ge, R. Xu, Z. Lin. Angew. Chem. Int. Ed., 55 (2), 7898 (2016).

[2] J.-H. Yun, Y.C. Park, J. Kim, H-J. Lee, W.A. Anderson, J. Park. Nanoscale Res. Lett., 6 (1), 287 (2011).

[3] Y. Jung, S.W. Nam, R. Agarwal. Nano Lett., 11 (3), 1364 (2011).

[4] L. Tang, S.E. Kocabas, S. Latif, A.K. Okyay, D.-S. Ly-Gagnon, K.C. Saraswat, D.A.B. Miller. Nature Photonics, 2, 226 (2008).

[5] J. Andzane, N. Petkov, A.I. Livshits, J.J. Boland, J.D. Holmes, D. Erts. Nano Lett., 9 (5), 1824 (2009).

[6] V. Schmidt, U. Gösele. Science, 316, 698 (2007).

[7] X. Liang, Y. Kim, D. Gebergziabiher, J. Stickney. Langmuir, 26, 2877 (2010).

[8] M. Wu, G. Vanhoutte, N.R. Brooks, K. Binnemans, J. Fransaer. Phys. Chem. Chem. Phys., 17, 12080 (2015).

[9] N. Chandrasekharan, S.C. Sevov. J. Electrochem. Soc., 157, 140 (2010).

[10] R. Al-Salman, J. Mallet, M. Molinari, P. Fricoteaux, F. Martineau, M. Troyon, S. Zein El Abedin, F. Endres. Phys. Chem. Chem. Phys., 10, 6233 (2008).

[11] X. Li, G. Meng, Q. Xu, M. Kong, X. Zhu, Z. Chu, A-P. Li. Nano Lett., 11 (4), 1704 (2011).

[12] A.I. Carim, S.M. Collins, J.M. Foley, S.J. Maldonado. Am. Chem. Soc., 133, 13292 (2011).

[13] E. Fahrenkrug, J. Biehl, S. Maldonado. Chem. Mater., 27, 3389 (2015).

[14] S. Usui, T. Yamasaki, J. Shimoizaka. J. Phys. Chem., 71 (10), 3195 (1967).

[15] J. Gu, S.M. Collins, A.I. Carim, X. Hao, B.M. Bartlett, S. Maldonado. Nano Lett., 12 (9), 4617 (2012).

[16] D.G. Gromov, S.A. Gavrilov. Heterogeneous Melting in LowDimensional Systems and Accompanying Surface Effects, Thermodynamics - Physical Chemistry of Aqueous Systems Dr.. ed. by Juan Carlos Moreno PirajÃn (INTECH Open Access Publisher, 2011) ch. 7, p. 157.

[17] Д.Г. Громов, Л.М. Павлова, А.И. Савицкий, А.Ю. Трифонов. ФТТ, 57 (1), 163 (2015).

[18] N.K. Mahenderkar, Y.-C. Liu, J.A. Koza, J.A. Switzer. ACS Nano, 8 (9), 9524 (2014).

[19] Д.Г. Громов, С.А. Гаврилов. ФТТ, 51 (10), 2012 (2009).

[20] А.П. Бабичев, Н.А. Бабушкина, А.М. Братковский. Фuзические величины (М., Энергоатомиздат., 1991) гл. 14, c. 330 .

[21] Л.В. Гурвич, И.В. Вейц, В.А. Медведев. Термодинамические свойства индивидуальных веществ. Справочное издание в 4-х т. (М., Наука, 1981) т. III, кн. 1, гл. 23, с. 189.

[22] Л.В. Гурвич, И.В. Вейц, В.А. Медведев. Термодинамические свойства индивидуальных веществ. Справочное издание в 4-х т. (М., Наука, 1979) т. II, кн. 1, гл. 18, с. 294. 
[23] М. Хансен, К. Андерко. Структура двойных сплавов (М., Металлургиздат, 1962) т. 1, с. 812.

[24] M. Wautelet, J.P. Dauchot, M. Hecq. Nanotechnology, 11, 6 (2000).

[25] G. Garzel, J. Janczak-Rusch, L. Zabdyr. Calphad, 36, 52 (2012).

Редактор Г.А. Оганесян

\section{The electrolyte temperature influence on cathodic deposition process of Ge nanowires on In and $\mathrm{Sn}$ particles in aqueous solutions}

I.M. Gavrilin ${ }^{1}$, D.G. Gromov ${ }^{1}$, A.A. Dronov ${ }^{1}$, S.V. Dubkov ${ }^{1}$, R.L. Volkov ${ }^{1}$, A.Y. Trifonov ${ }^{1,2}$, N.I. Borgardt ${ }^{1}$, S.A. Gavrilov ${ }^{1}$

${ }^{1}$ National Research University of Electronic Technology, 124498 Zelenograd, Russia

${ }^{2}$ Federal State Unitary Enterprise Lukin Research Institute of Physical Problems, 124460 Zelenograd, Russia

Abstract This work presents the study of filamentous Ge structures growth in aqueous electrolytes at different temperatures using In and Sn nanoparticle arrays as a nucleation sites. It is found that the temperature of $\mathrm{Ge}$ cathodic deposition process in aqueous solutions significantly affects on the layer structure deposited on the surface. In the presence of metal particles in the molten condition, filamentary Ge structures growth occurs by cathodic reduction of Ge-containing ions at the electrode surface, followed by dissolving and crystallizing the melt at the substrate interface. These results demonstrate a crucial role of the liquid metal particles presence on the electrochemical germanium nanowires growth process. 